\title{
Screening for cervical neoplasia in a health center in Western Andalusia
}

\author{
Concepción Duclós-García ${ }^{1}$, Carmen Pareja-Arcos ${ }^{1}$, Manuel Ortega-Calvo ${ }^{2^{*}}$ \\ ${ }^{1}$ Bellavista Health Center, Seville, Spain \\ ${ }^{2}$ Esperanza Macarena Health Center, Instituto de Salud Carlos III, Seville, Spain \\ Email: ${ }^{*}$ ortegacalvo@terra.es
}

Received 27 September 2011; revised 16 December 2011; accepted 18 January 2012

\begin{abstract}
We have analyzed the annual burden of 736 smears collected in the screening of cervical neoplasia at primary care facility where we work. We could not detect any neoplasia. Of the 50 positive smears $(6.79 \%$ of total), 4 cases showed HSIL (high grade intraepithelial lesion) (median age 32 years) and 10 cases had LSIL (low grade intraepithelial lesion) (median age 25.5 years). The median age of the 733 satisfactory smears was 40 years. Age was a significant predictor for having an altered cytology $(\mathrm{OR}=0.96,95 \% \mathrm{CI}=$ 0.93 to $0.98, p=0.001190$ ). Candida albicans was the microorganism more frequently associated with nonneoplastic inflammatory changes.
\end{abstract}

Keywords: Primary Care; Cervical Neoplasia; Pap Test; Logistic Regression; Secondary Prevention

\section{INTRODUCTION}

Cervical cancer is the second most common malignant neoplasm among women worldwide in developed countries [1]. In the late 90's it was found an increased mortality in our country through a gompertzian analysis [2]. Mortality appears to be declining in the first decade of the century [3] although perhaps due to problems of misclassification on death certificates, there is still an increase in mortality in the cohort of younger women [4].

Using data from the Cancer Registry of Granada some years ago obtained a standardized incidence rates by age of women 6.13/100.000 for the period 1993-1997 [5]. In the south of Spain were held years ago prevalence studies [6].

Primary prevention is characterized by health promotion to promote lifestyles and behaviours to minimize the risk of cervical cancer. Interventions to promote condom use for sexual intercourse (especially early intercourse among young women), the reduction of sexual partners

${ }^{*}$ Corresponding author. and negotiating strategies for safer sex have been recommended as an approach to limit the spread of virus Human Papillomavirus (HPV), one of the most important risk factors for cervical cancer [7]. Although it appears that social class and educational attainment are also very important $[8,9]$. The HPV prophylactic vaccines are recommended before the onset of sexual activity and exposure although there are critical opinions about it $[10,11]$.

Secondary prevention is the Pap test or Pap smear. The Pap test screening is based on the morphological study of cells obtained by exfoliation of the cervical epithelium and its objective is early detection of preinvasive lesions of the cervix in asymptomatic women.

The scientific evidence on the effectiveness of early detection of cervical cancer does not come from randomized trials but from observational studies of casecontrol and cohort studies conducted in the United States, Canada and some European countries where trends are compared seasonal incidence and mortality in different populations.

As a major health problem with a tough method of secondary prevention such as the implementation of the Pap smear, we decided to analyze the distribution of results in Pap tests performed during a year in the primary care setting where we job.

\section{METHODOLOGY}

Using a retrospective observational study we have analyzed the health burden of Pap smears in a primary care facility for the program to prevent uterine cervix neoplasm.

The fundamental variables have been the age of the women gathered in years and the result of cytology. Cytology was considered positive if it contained lesions diagnosed as precancerous. And it was considered negative when there was no absence of precancerous lesions and invasive cancer of the uterine cervix, although other organisms such as Trichomonas appear, Candida or Actinomyces. The collection of data has been extracted 
from the pathology reports from "Ciudad Sanitaria Virgen del Rocio" from January 1, 2009 to December 31 of that year.

Pap results are classified according to the "Bethesda cytologic classification 2001" for reporting cervicalvaginal cytology [12]. Those to be considered positive preneoplastic and neoplastic changes occur "in situ". Be considered negative are those who have no intraepithelial lesion or malignancy, but if they have non-neoplastic cellular changes and infections caused by organisms such as Trichomonas, Candida, Actinomyces and other bacteria. It was prepared a categorical variable for different types of Bethesda classification and a variable [12] also categorical that a positive or negative.

The results are collected in an Excel file and then analyzed by $\mathrm{R}$ [13]. Was performed descriptive statistics with means and medians and corresponding measures of dispersion. Age variable F testing compared variances. Predictive models were conducted by binary logistic regression analysis for the cytology variable (negative/ positive) as a dependent.

We did not perform sample size study because the intent of our work was to measure and describe the annual charge. Once collected all Pap and knowing the sample size was made inferences about the magnitudes of the OR detectable by logistic models [14].

Permission was requested from the Local Ethics Committee and was informed this descriptive project favourably.

\section{RESULTS}

We obtained a total of 736 Pap smears for a year's work (2009), of which only three were unsatisfactory for evaluation. The median age for satisfactory sample was 40 years while for unsatisfactory was 26 years. At Table 1 are described the statistics of central tendency, dispersion and quartiles (733 satisfactory smears). Figure $\mathbf{1}$ is exposed bar chart of the different abnormalities collected by Bethesda nomenclature.

Figure 2 shows the box and whiskers plot of the age variable distributed between groups of changes in classi- fication of Bethesda. As can be seen the median age of 4 cases of HSIL (high grade intraepithelial lesion) was 32 years and the median of the 10 cases of LSIL (low grade intraepithelial lesion) was 25.5 years. In Figure 3 is the graph of boxes and whiskers of the age variable with regard to all sorted by positive smears $($ code $=1)(n=50)$ or negative $($ code $=0)(n=686)$. The F test for compareson of variance in this variable $(\mathrm{Cgral} 2 \mathrm{rec})$ was not significant $(\mathrm{F}=0.8427 \mathrm{p}=0.36)$.

Of the total of 736 Pap smears, only 50 showed some abnormality (6.79\%). Not misled any "in situ" carcinoma. Table 2 shows the binary logistic regression model with age as a predictor variable $(\mathrm{OR}=0.9613,95 \% \mathrm{CI}=0.98$ to 0.93 ). At Table 3 is described the $\mathrm{R}$ syntax used to recode the variable "Categorización.Gral2." Figure 4 shows the different bacteria found in non preneoplastic smears.

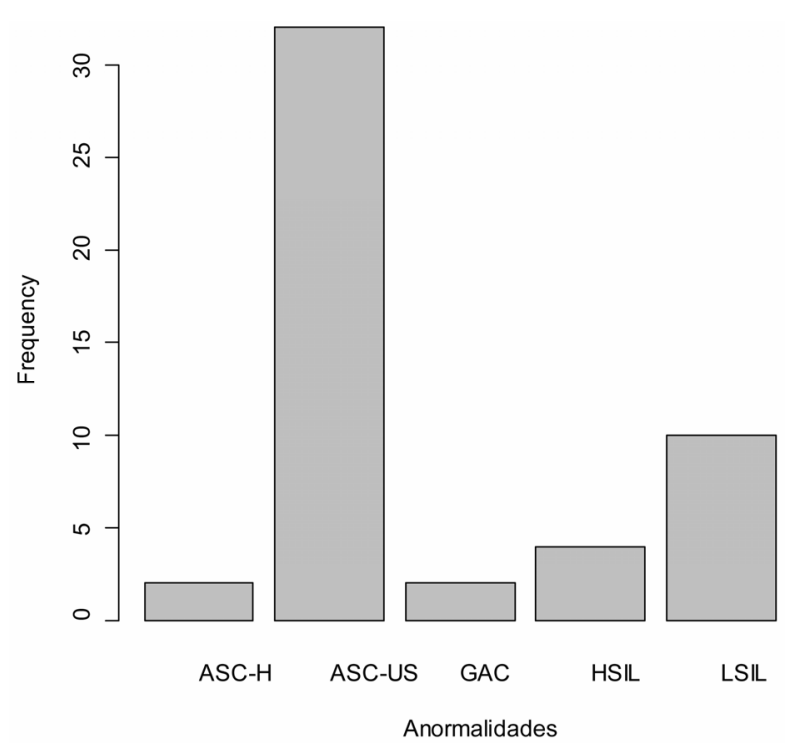

Figure 1. Abnormalities detected in the sample according to the Bethesda nomenclature. ASC-H (squamous intraepithelial lesion high grade). ASC-US (atypical squamous cells of undetermined significance). GAC (atypical glandular cells of undetermined significance). HSIL (high grade intraepithelial lesion). LSIL (low grade intraepithelial lesion).

Table 1. Age variable distribution.

\begin{tabular}{ccccccc}
\hline Arithmetic mean & Standard deviation & Percentile 0 & Percentile 25 & Percentile 50 & Percentile 75 & Percentile 100 \\
\hline 37.78 & 12.34 & 15 & 27 & 40 & 47 & 67 \\
\hline
\end{tabular}

Table 2. Binary logistic regression model with the covariable age expressed in years. When completing a year is less likely cytological alteration in our sample $(\mathrm{p}<0.01)$.

\begin{tabular}{ccccc}
\hline Result variable & Covariable & $\beta_{0}$ & Odds ratio & $95 \%$ Confidence intervals \\
\hline Altered cytology & Age in years & -1228 & 0.9613 & $0.9842-0.9389$ \\
\hline
\end{tabular}




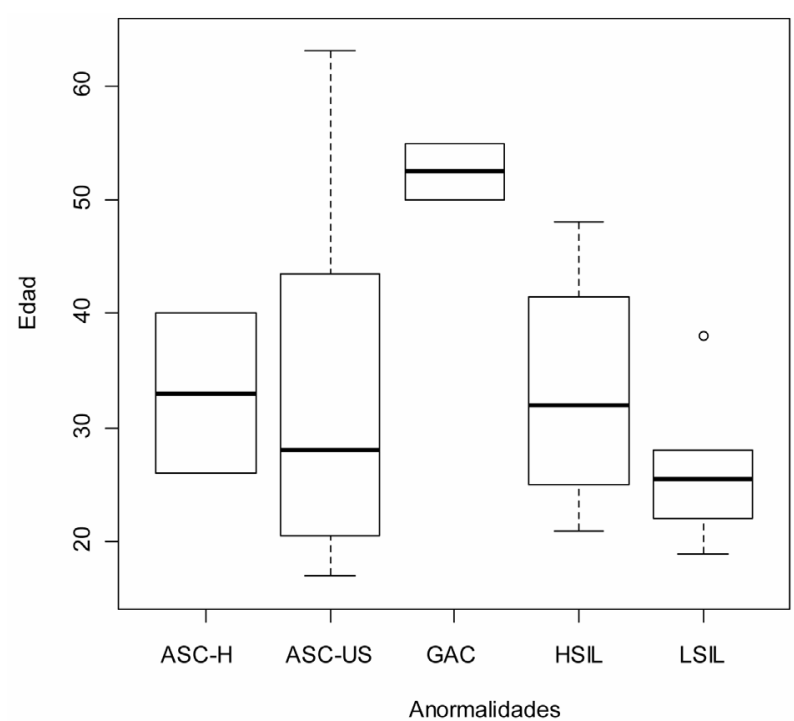

Figure 2. Box and Whiskers plot of the age variable according to the Bethesda classification abnormalities. ASC-H (squamous intraepithelial lesion high grade). ASC-US (atypical squamous cells of undetermined significance). GAC (atypical glandular cells of undetermined significance). HSIL (high grade intraepithelial lesion). LSIL (low grade intraepithelial lesion).

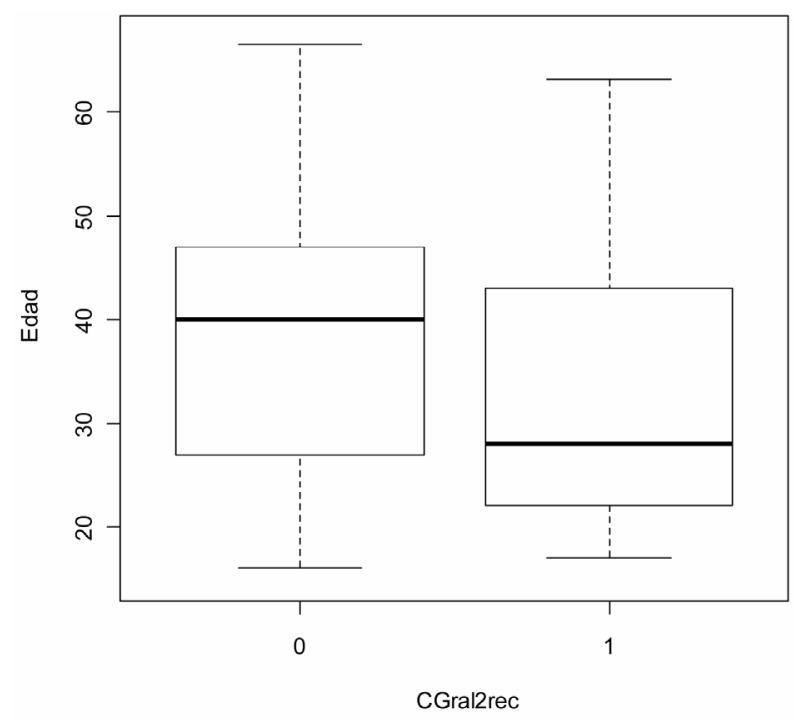

Figure 3. Box and Whiskers Plot of the variable age in years with regard to all sorted by positive smears (1) or negative (0) (Variable CGral2rec). In an univariate logistic regression model, age was a predictor of cytological disturbance $(\mathrm{p}<0.01)$ (Table 2).

\section{DISCUSSION}

Although there were no a priori sample calculations, as we mentioned above, with a sample size of 736 is operated by a wide margin of accuracy in the logistic regression models, if you follow the rule of ten events of interest per variable (in the case also in this case an univariate model as the one shown in Table 2) [14]. Although there
Table 3. Syntax used in $\mathrm{R}$ commander to recode the variable "Categorización.Gral2" making it feasible for a binary logistic regression analysis (Variable recoded CGral2rec). (Papsmear is the name of the data packet; "Negativa PIM" is the tag of negativity from the source variable). Post recodification quality control shows observed data distribution (686 negative and 50 positive smears).
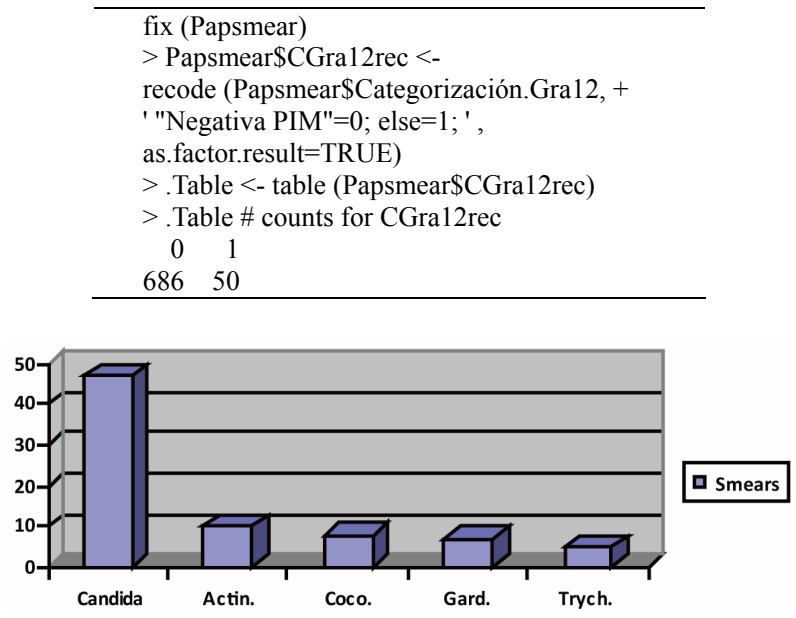

Figure 4. A descriptive study of the etiology in cases of inflammatory lesions by microorganisms (Candida = Candida; Actin $=$ Actinomyces; Coco $=$ coccobacilli; Gard $=$ Gardenella, Trych $=$ Tryconomas).

have been no comparisons with the population pyramid, we inferred that our sample is representative of the population served.

The first comment is that there has been no case of cervical cancer for an annual burden of 736 Pap smears. Figures 1 and $\mathbf{2}$ are reflected frequency distributions of preneoplastic changes according to the Bethesda classification [12]. We noted 4 cases of HSIL detected with a median age of 32 who are following a comprehensive control and two cases of ASC-H with a median age of 33 years in the same circumstances. These results seem consistent with others published in our country [15].

Of the 736 smears examined only 50 showed preneoplastic changes. Figure 3 shows the boxes and whiskers plot viewed from the perspective of age. The variable "CGral2rec" comes from the remodified variable "Categorización.Gral2" that presented some problems in the original data package for statistical treatment (Table 3). We deemed it necessary to include this table for R, which is a free software is increasingly used in epidemiological studies over [13,16,17]. Robert Gentleman and Ross Ihaka of the Statistics Department at the University of Auckland developed R [13]. Subsequently it has been joined by many researchers who have donated their contributions to the initial group ( $\mathrm{R}$ Core Group) and $\mathrm{R}$ Foundation. 
Were not collected variables of social class or socioeconomic status that would allow comparing our results with others published from our own region [18]. Not taken into account the variable pregnancy [19].

In the 77 cases that were found non-neoplastic cell changes more infection, none corresponds to HPV (Figure 4). No cases of Lactobacillus were detected [20]. Also noteworthy are the 10 cases of actinomyces in a total of 77 (12.98\% of women who had non-neoplastic inflammatory changes). We are not able to tell if these women were not carriers of IUD [21]. The results obtained using binary logistic regression showed that women who composed our sample showed a higher probability of getting no upsets as they gain one year (OR $=0.96,95 \%$ CI 0.98 to 0.93 ) (Table 2). Statistically speaking this is equivalent to a $\mathrm{T}$ model with the predictor of continuous type.

In summary, we communicate in this article a descriptive and analytical study of 736 Pap smears that we collected in our primary care facility during 2009, highlighting the 4 cases of HSIL and 10 cases of LSIL detected, all currently tracked and 10 cases of actinomycosis as non-neoplastic inflammatory lesions. We believe that screening for cervical neoplasia in primary care is a necessary activity [22,23]. We have detected any negative experiences in these women should be included in the calculations of cost-effectiveness and cultural barriers [24,25]. The HPV vaccination strategy should be monitored in the short, medium and long term $[10,11$, 26].

\section{REFERENCES}

[1] Vioque, J. and Fenollar, J. (1995) The distribution of cervical cancer mortality in Spain (1981-1986). An ecological study. Medicina Clínica, 104, 287-292.

[2] Llorca, J., Prieto, M.D. and Delgado-Rodríguez, M. (1999) Increase in cervical cancer mortality in Spain, 1951-1991. Journal of Epidemiology \& Community Health, 53, 408411. doi:10.1136/jech.53.7.408

[3] Rodríguez-Rieiro, C., Aragonés, N., Pollan, M., LópezAbente, G. and Pérez-Gómez, B. (2009) Temporal trends of cervical cancer mortality rates among regions in Spain: 1975-2004. Medicina Clínica, 133, 41-46.

[4] Llorca, J., Rodriguez-Cundin, P., Dierssen-Sotos, T. and Prieto-Salceda, D. (2006) Cervical cancer mortality is increasing in Spanish women younger than 50. Cancer Letters, 240, 36-40. doi:10.1016/j.canlet.2005.08.021

[5] Puig-Tintoré, L.M., Castellsagué, X., Torné, A., De Sanjosé, S., Cortés, J., Roura, E., Méndez, C. and Bosch, F.X. (2008) Coverage and factors associated with cervical cancer screening: Results from the AFRODITA study: A population-based survey in Spain. Journal of Lower Genital Tract Disease, 12, 82-89.

[6] Ortega Calvo, M., Martínez Manzanares, C., Manzanares
Torné, M.L., Pérez Torres, I., Sánchez Bursón, J.M., López Montes, M. and Pino Mejías, R. (1987) Epidemiología Analítica del Cérvix Neoplásico en el sur de España. Revista Clínica Española, 181, 534-538.

[7] De Sanjose, S., Quint, W.G., et al. (2010) Human papillomavirus genotype attribution in invasive cervical cancer: A retrospective cross-sectional worldwide study. Lancet Oncology, 11, 1048-1056. doi:10.1016/S1470-2045(10)70230-8

[8] Franceschi, S., Plummer, M., et al. (2009) Differences in the risk of cervical cancer and human papillomavirus infection by education level. British Journal of Cancer, 101, 865-870. doi:10.1038/sj.bjc.6605224

[9] Bosch, F.X. and De Sanjosé, S. (2007) The epidemiology of human papillomavirus infection and cervical cancer. Disease Markers, 23, 213-227.

[10] Márquez Calderón, S. (2008) The human papilloma virus vaccine: Reflections on the dissemination process, scientific evidence and doubts. Enfermería Clínica, 18, 55-58.

[11] Márquez Calderón, S., Lopez-Valcarcel, B.G. and Segura, A. (2009) Medical societies' recommendations for immunization with Human Papillomavirus vaccine and disclosure of conflicts of interests. Preventive Medicine, 48, 449-453. doi:10.1016/j.ypmed.2009.02.018

[12] Mody, D.R., Nayar, R. and Thrall, M. (2011) Bethesda System classification of glandular lesions on cervical cytology. Monographs in Clinical Cytology, 20, 5-14.

[13] Ihaka, R. and Gentleman, R.R. (1996) A language for data analysis and graphics. Journal of Computational and Graphical Statistics, 5, 299-314.

[14] Ortega Calvo, M. and Cayuela Domínguez, A. (2002) Regresión logística no condicionada y tamaño de muestra: Una revisión bibliográfica. Revista Española de Salud Pública, 76, 85-93. http://www.scielosp.org/pdf/resp/v76n2/a02v76n2.pdf

[15] Oncins, R., Fuente, C. and Nájar, M. (2001) Estudio descriptivo de los casos de neoplasia intraepitelial grado III (CIN III) en el área del Hospital de Barbastro. Atención Primaria, 28, 457-462.

[16] Nicodemus, K.K. (2008) Catmap: Case-control and TDT meta-analysis package. BMC Bioinformatics, 9, 130. doi:10.1186/1471-2105-9-130

[17] Cáceres, A., Armengol, L., Villatoro, S. and González, J.R. (2011) MLPAstats: An R GUI package for the integrated analysis of copy number alterations using MLPA data. BMC Bioinformatics, 12, 147. doi:10.1186/1471-2105-12-147

[18] Ocaña-Riola, R., Sánchez-Cantalejo, C., Rosell, J., Sánchez-Cantalejo, E. and Daponte, A. (2004) Socio-economic level, farming activities and risk of cancer in small areas of Southern Spain. European Journal of Epidemiology, 19, 643-650. doi:10.1023/B:EJEP.0000036808.26094.43

[19] Loomis, D.M., Pastore, P.A., Rejman, K., Gutierrez, K.L. and Bethea, B. (2009) Cervical cytology in vulnerable pregnant women. Journal of the American Academy of Nurse Practitioners, 21, 287-294.

[20] Lamont, R.F., Sobel, J.D., Akins, R.A., Hassan, S.S., 
Chaiworapongsa, T., Kusanovic, J.P. and Romero, R. (2011) The vaginal microbiome: New information about genital tract flora using molecular based techniques. BJOG: An International Journal of Obstetrics and Gynaecology, 118, 533-549.

http://onlinelibrary.wiley.com/doi/10.1111/j.1471-0528.2 010.02840.x/pdf

[21] Merki-Feld, G.S., Rosselli, M. and Imthurn, B. (2008) Comparison of two procedures for routine IUD exchange in women with positive pap smears for actinomyces-like organisms. Contraception, 77, 177-180. doi:10.1016/j.contraception.2007.11.007

[22] Wiesner-Ceballos, C., Murillo Moreno, R.H., Piñeros Petersen, M., Tovar-Murillo, S.L., Cendales Duarte, R. and Gutiérrez, M.C. (2009) Control del cáncer cérvicouterino en Colombia: La perspectiva de los actores del sistema de salud. Revista Panamericana de Salud Pública, 25, 1-8. doi:10.1590/S1020-49892009000100001
[23] Ibrahim, A., Rasch, V., Pukkala, E. and Aro, A.R. (2011) Cervical cancer risk factors and feasibility of visual inspection with acetic acid screening in Sudan. International Journal of Women's Health, 3, 117-122. doi:10.2147/IJWH.S14189

[24] Curtis, D. (2011) Patient experience-The ingredient missing from cost-effectiveness calculations. Patient Prefer Adherence, 5, 251-254. doi:10.2147/PPA.S20243

[25] Fort, V.K., Makin, M.S., Siegler, A.J., Ault, K. and Rochat, R. (2011) Barriers to cervical cancer screening in Mulanje, Malawi: A qualitative study. Patient Prefer Adherence, 5, 125-131.

[26] Álvarez-Soria, M.J., Hernández-González, A., CarrascoGarcía, De León, S., Del Real-Francia, M.Á., GallardoAlcañiz, M.J. and López-Gómez, J.L. (2011) Demyelinating disease and vaccination of the human papillomavirus. Revista de Neurología, 52, 472-476. 